\title{
Local Institutions and the Dynamics of Community Sorting
}

\author{
By ANDREA RoBbetT*
}

\begin{abstract}
This paper studies the dynamics by which populations with heterogeneous preferences for public good provision sort themselves into communities. I conduct laboratory experiments to consider which institutions best facilitate efficient self-organization when residents can move freely between locations. I find that institutions requiring all residents of a community to pay equal taxes enable subjects to sort into stable, homogeneous communities. Though sorted, residents often fail to attain the provision level best suited for them. When residents can vote for local tax policies with ballots, along with their feet, each community converges to the most efficient outcome for its population. (JEL C73, D72, H21, H41, H71, H73)
\end{abstract}

mericans are a highly mobile population, with 12 to 15 percent of residents moving to a new location each year. ${ }^{1}$ A significant question is how individuals choose their communities and, in doing so, sort themselves geographically. At the same time, one of the most important roles of local communities is to provide public goods and services, such as roads, schools, libraries, police, and fire protection, and so forth. Residents typically vary in their demand for these services, and how to provide them efficiently in light of this heterogeneity is a central problem of public economics.

The cornerstone of local public finance is the Tiebout model (1956), which suggests that mobility can provide a market-based solution to the problem of demand revelation. If households can move freely between jurisdictions, Tiebout proposed that residents will vote with their feet and move to the community where the local taxes and public expenditures best suit them. In doing so, they will sort themselves by their preferences and can then be taxed according to their demand. Thus, optimal public good provision can be achieved at the community level.

The model's underlying premise, that mobility can lead to efficient outcomes, has been subsequently applied to areas far beyond public economics, including coalition formation, consumer choice, and labor market sorting. However, it is unclear whether the ability to vote with one's feet does in fact lead to the formation of optimal communities. Since the inability to measure a household's true demand for public goods is the central motivation for Tiebout's proposal, it is perhaps unsurprising

\footnotetext{
* Department of Economics, Middlebury College, Middlebury, VT 05753 (e-mail: arobbett@middlebury.edu). I thank Charles Plott, Leeat Yariv, Rod Kiewiet, John Ledyard, Jean-Laurent Rosenthal, and the Harvard Decision Science Laboratory.

Go to http://dx.doi.org/10.1257/mic.6.3.136 to visit the article page for additional materials and author disclosure statement(s) or to comment in the online discussion forum.

${ }^{1}$ Averaging over the past decade, 13.5 percent of Americans have moved per year (Bureau of the Census 2000-2010).
} 
that attempts to directly test whether migration patterns are driven by preferences have proven difficult and that the evidence has often been varied and inconclusive. But public goods preferences can be readily generated in laboratory experiments by adjusting the payoffs that subjects receive from the outcome of a public goods game, and the dynamics of community formation may then be observed in a controlled environment. In addition, experiments can test the effectiveness of various institutions in facilitating efficient provision that would otherwise be very costly to assess in the field.

This is the approach taken in this paper and, ultimately, the findings reported here suggest that the ability to vote with one's feet is not sufficient for achieving optimal allocations. However, when subjects can vote for local tax rates with their ballots, as well as with their feet, optimal outcomes are typically reached. These results indicate the importance of local governance, in conjunction with mobility, in achieving efficient local outcomes-both in public finance and in the variety of domains to which the Tiebout model has been applied.

This paper considers a simple environment with three natural properties. First, the population has heterogeneous preferences for the public good: there are those who greatly benefit from the public good provided within their community, and those who benefit very little. Second, the preferences of the agents are unobservable to others, and so a single community cannot charge different prices to different preference types. Finally, there are multiple locations and agents have full mobility between them. These experiments are not intended as a precise depiction of local public finance and residential choice in all its complexity, but, rather, as an attempt to gain insight into the fundamental mechanism and processes that Tiebout envisioned by studying movement decisions within this simple environment.

The goals of this paper are: (i) to consider whether mobility is, in itself, sufficient for achieving optimal public good provision; (ii) to analyze the dynamics that may prevent optimality from being reached; and (iii) given these dynamics, to assess which institutions may be most successful in facilitating efficient self-organization.

Four experimental conditions were conducted, each corresponding to an institution governing how public good contributions are determined. The first is the standard voluntary provision mechanism, which allows residents to contribute different amounts within the same community and is therefore susceptible to free riding. This corresponds to the baseline that Tiebout's model was proposed to improve upon. It is compared with three different provision mechanisms requiring all residents of a community to make the same contribution by means of a local tax. Under the first such institution, each location is associated with a different fixed, posted tax rate that remains the same for the duration of the experiment, and all subjects must contribute this amount in each period that they reside there. Among the locations are those offering the optimal tax rates for each of the preference types. Similarly, under the second institution, each location is associated with a fixed, posted total contribution level, and all subjects must contribute an equal share of this amount. These institutions reflect Tiebout's assumption that there exists a large number of available communities, representing a complete range of expenditure packages that are "more or less set" (Tiebout 1956, 418). The final institution incorporates a simple form of local governance that is responsive to the preferences of the current population. In 
each period, the location's current members vote on the tax rate, the median voter's preference is implemented, and all residents are required to contribute this amount.

I find, first, that the voluntary contribution communities are highly unstable. The subjects continually move between locations throughout the experimental session and this chronic movement leads to efficiency significantly below even that predicted under the Nash equilibrium for a single, fixed community.

Under all three of the institutions requiring all members of a community to make equal contributions, subjects separate by type into an optimal partition. When they are able to vote only with their feet, by moving between communities offering fixed taxes or provision levels, subjects often become stuck at local, inefficient equilibria such that they under- or over-provide the public good. Though they sort into separate, homogeneous communities, the subjects often fail to attain the optimal provision within these communities, because they are unable to coordinate on the location offering the optimal tax-provision bundle for their type. This suggests that the ability to vote with one's feet is not sufficient for achieving optimal outcomes: the existence of communities with optimally designed local tax policies does not guarantee that they will be entered, and inertia can prevent optimality from being reached.

Under the voting institution, residents can vote both with their feet and with ballots. The subjects vote to enact their optimal tax rates, and the communities converge to the optimal outcomes for their populations. The ability to vote with their feet enables the subjects to sort by type, while the ability to vote with their ballots enables them to then adjust the community policy once they have arrived. This suggests that an internal mechanism that allows residents to influence community policy without needing to relocate may be necessary for overcoming coordination failure and achieving optimal allocations. Although Tiebout did not address the question of local governance, these results suggest that both local politics and system dynamics may be essential for determining whether local public goods are provided efficiently.

The Tiebout model was not presented as a descriptive model of residential choice, but as an innovative "conceptual solution" to the problem of demand revelation. 2 Tiebout introduced the idea of local public goods that were geographically excludable: since they were available only to those living within a jurisdiction, anyone wishing to consume the local public good would have to move into the community and pay the associated local taxes. Rather than relying on residents to truthfully report their preferences within a community, Tiebout proposed that they would reveal their true preferences by relocating to the community that perfectly matched their needs.

Since the appearance of Tiebout's work, the theoretical literature has filled in and extended Tiebout's sparse framework, formalizing his insights while incorporating housing prices, land provision, spillovers and crowding, as well as considering income heterogeneity and redistribution, and analyzing the determination of public good supply and its political requirements. This literature suggests that sorting may be difficult to achieve, and whether an efficient allocation is reached often depends

\footnotetext{
${ }^{2}$ Tiebout $(1956,424)$. Oates (2006) provides a discussion of whether Tiebout intended his paper as a descriptive theory or purely as a clever thought experiment.
} 
on the specifics of the environment. The goal of this paper is to strip away this complexity, return to the simplified setting that Tiebout addressed, and to study the underlying dynamics of the residential sorting process in the absence of specific environmental factors.

One approach has been to complete Tiebout's analogy of local public goods as private goods, by integrating the model into a general equilibrium setting. This work has largely found that Tiebout's proposition holds only under highly restrictive conditions. ${ }^{3}$ The general equilibrium interpretation is reflected here in the experimental sessions that offer agents a wide range of fixed expenditure packages. An alternative approach departs from Tiebout's assumptions by incorporating models of local governance and considers the simultaneity of selecting a community and voicing political preferences while there..$^{4}$ These models have primarily focused on majority rule, and are captured by the voting institution considered in this paper.

There is also a vast empirical literature aimed at testing the implications of the Tiebout model within communities in the United States. Many studies have shown local sorting along demographic factors, such as income, race, and education, as well as by political and cultural preferences. ${ }^{5}$ However, the extent to which residents move in response to their preferences for public goods, sort into communities where other residents share their preferences, and consume their optimal package of local services, is far less clear (Dowding, John, and Biggs 1994). 6

The difficulty in measuring public goods preferences and how they drive movement decisions suggests that laboratory experiments can be particularly useful in understanding the mechanisms of residential choice and community sorting. The experiments in this paper, which allow agents with different preferences to sort by local tax rates and provision levels, are, to my knowledge, the first of their kind, but build on recent experiments on voluntary public good provisions in endogenously formed groups. Voluntary contributions experiments in fixed groups have consistently found that contributions are initially midway between optimal and Nash equilibrium levels, but quickly decline and approach the equilibrium (Ledyard 1995).

Experiments that allow subjects to select their group in each period have shown that free mobility is not sufficient to sustain contributions and, if movement is unrestricted, free riders will chase cooperators from location to location (Ehrhart and Keser 1999). Implementation of formal boundary rules or other mechanisms that current members may use to control group composition have been successful at increasing contributions, though subjects are sometimes prone to over exclusion. 7

\footnotetext{
${ }^{3}$ See Wooders (1999) for an overview.

${ }^{4}$ For instance, Westhoff (1977); Epple, Filimon, and Romer (1984, 1993); Konishi (1996); Kollman, Miller, and Page (1997).

${ }^{5}$ See, for instance, Costa and Kahn (2000) and Bishop (2008).

${ }^{6}$ Consistent with Tiebout's assumptions, American cities vary greatly in public services provided and demanded (see, Gramlich and Rubinfeld 1982; Stein 1987). While survey data have suggested that a household's decision to move is rarely based on public expenditures (Rhode and Strumpf 2003), there is also considerable evidence that public services and taxes are significant factors in neighborhood choice once a household has already decided to move (Reschovsky 1979; Fox, Herzog, and Schlottman 1989; Percy, Hawkins, and Maier 1995). However, the few direct tests of migration based on local policy changes have produced conflicting conclusions (see, for instance, Been and Gupta 1997; Cameron and McConnaha 2006; Banzhaf and Walsh 2008; and Greenstone and Gallagher 2008 for conflicting evidence on migration in response to environmental impacts).

${ }^{7}$ Page, Putterman, and Unel (2005); Ahn, Isaac, and Salmon (2008, 2009); Charness and Yang (2010).
} 
Experiments have also shown that subjects will vote with their feet for institutions allowing them to punish free-riders (Gürerk, Irlenbusch, and Rockenbach 2006).

When subjects differ in the returns that they receive from the public good, there is a clear dynamic in which high demanders repeatedly form new groups with high provision. They are then followed by others, provision declines, and the cycle restarts (Robbett 2010). This chasing phenomenon persists even when the public good is purely nonrivalrous, such that there is never monetary incentive to exit large groups. This suggests that people are often unwilling to remain where others are contributing less than they are, and so group stability may be contingent upon requiring equal contributions from all members, as in the three tax institutions considered in this paper.

\section{Environment}

I consider a basic Tiebout-style environment, in which residents may move between communities providing different quantities of the public good. In each time period, all agents simultaneously select their location, where they receive a payoff that is increasing over public good provision in the community and decreasing over the amount that they personally contribute toward provision.

There is a finite set of agents, $\mathcal{N}=\{1, \ldots, n\}$, and of locations, $\mathcal{L}=\{1, \ldots, k\}$.

A state $(\mathbf{l}, \mathbf{x})$ is an $n$-tuple of locations $\mathbf{l}=\left(l^{1}, \ldots l^{n}\right)$, where $l^{i}$ is an integer between 1 and $k$, and an $n$-tuple of contributions $\mathbf{x}=\left(x^{1}, \ldots, x^{n}\right)$. In other words, $l^{i}$ denotes where agent $i$ resides, and $x^{i}$ is agent $i$ 's contribution.

The feasible values of $\mathbf{x}$ follow one of two cases. In the first case, contributions are voluntary and, for all $i, x^{i}$ may be any number greater than or equal to 0 . In the second case, contributions are uniform for all members of a location, such that for any two agents $i$ and $j, l^{i}=l^{j}$ implies that $x^{i}=x^{j}$. In this case, there is a mapping $t: \mathcal{L} \Rightarrow \mathbf{R}^{+}$such that $x^{i}=t\left(l^{i}\right)$. In other words, $t(l)$ describes the local tax associated with location $l$ that all residents must contribute in each period that they reside there.

There exists a public good with three notable properties. First, the public good is purely nonrivalrous, such that it is not depleted by the presence of additional community members. Second, it is produced at constant returns to scale. Specifically, the public good provided is equal to the total contributions. Finally, the public good is local and there are no spillovers between communities: an agent's contributions finance the public good only within his location and an agent receives a return from a location's public good if and only if he resides there.

Let $X^{j}$ be the quantity of the public good provided in location $j$. Then,

$$
X^{j}=\sum_{i \mid l^{i}=j} x^{i}
$$

The nonrivalry of the public good is a departure from Tiebout's assumptions. He suggested production technology as the motivation for providing public goods at the local level and assumed that communities face a per capita cost curve that is $\mathrm{u}$-shaped over the number of residents, implying an optimal community size that is less than the total population. 
These experiments consider a nonrivalrous public goods environment in order to study movement solely in response to preference differences, without the complication of crowding concerns that are particular to production technologies. In addition, if the population has highly divergent preferences and everyone within a location must pay a uniform local tax, then a pure public good in this environment need not imply that a population would prefer to cluster in a single location. The experimental design in this paper has the property that preference types would prefer to separate when community members face a uniform tax policy. Finally, the pure public good environment gives subjects the best possible shot at being comparatively successful in the voluntary contributions case, when free riding is the only obstacle to a society achieving the most efficient possible outcome by pooling its resources into a single community.

In each period, each agent $i$ receives a payoff from residing in location $l^{i}$ :

$$
\pi^{i}(\mathbf{l}, \mathbf{x})=A^{i} \ln \left(X^{i^{i}}\right)-x^{i} .
$$

Agents differ only in the parameter $A^{i}$, which determines their marginal rate of substitution between the public good and private consumption. ${ }^{8}$ It is easily shown that the best response of agent $i$ is to contribute the exact amount necessary to bring the collective community contributions to $A^{i}$ :

$$
x^{* i}=\max \left(0, A^{i}-\sum_{j \mid l^{j}=l^{i}, j \neq i} x^{j}\right) .
$$

This is the best response both myopically and in a game with a known, finite number of periods, as in the experimental design of this paper (described in detail in the next section). Thus, when agents are able to voluntarily contribute any amount to the public good, in equilibrium each community's total provision will equal the maximum value of $A$ represented in the community. However, the efficient level of provision for the community (which maximizes the aggregate payoffs of its residents) is equal to the sum of the parameters $A$ in the community. Therefore, when contributions are voluntary, the public good is under-provided in equilibrium.

Under an institution with uniform tax policies, all residents of community $j$ pay an equal tax, $t(j)$. In addition, let $n(j)$ denote the number of residents of community $j$. Then the payoff function in equation (2) becomes

$$
\pi^{i}(\mathbf{l}, \mathbf{x})=A^{i} \ln \left(t\left(l^{i}\right) \times n\left(l^{i}\right)\right)-t\left(l^{i}\right) .
$$

For any given number of residents, each agent has single peaked preferences over the community tax rates, such that $i$ 's utility is maximized at tax $t=A^{i}$. Thus, for each resident there is a trade-off between being in a large community and being in a

\footnotetext{
${ }^{8}$ This is a modification of the Cobb-Douglas preference function that has several useful properties-in particular, that agents are strictly better off as the level of public good in their community increases, that each type of agent has a preferred tax policy, and that an agent's best response is to contribute less than his preferred tax when contributions are voluntary.
} 


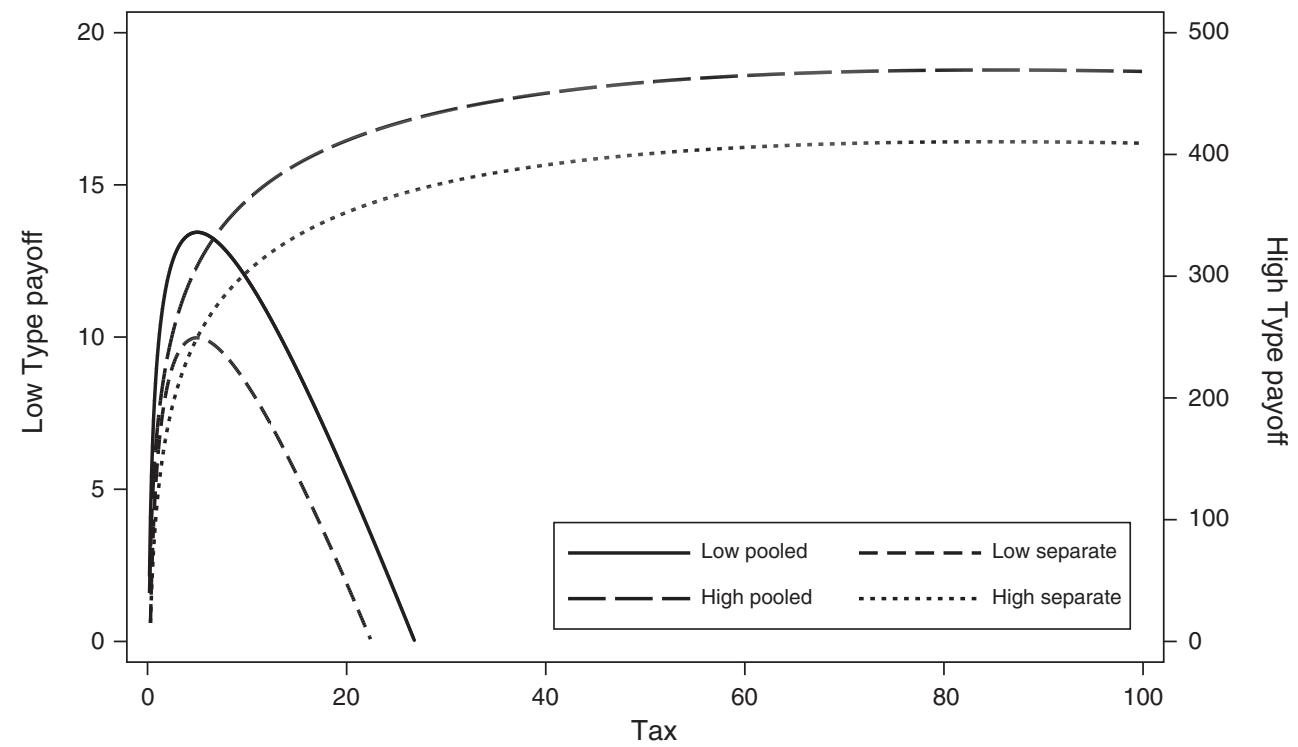

Figure 1. Payoff Functions for the Two Types in Communities of Size Eight (Pooled) or Four (Separate)

community where the tax is close to their ideal policy. When the values of $A$ in the society diverge sufficiently, as in the experiments described in the following section, there does not exist any intermediate tax rate that would make all agents better off pooling their resources than they would be sorting by type and consuming at their optimal taxes in smaller communities.

In the experiments in this paper, there are 4 agents for whom $A=5$ (Low Types) and 4 agents for whom $A=85$ (High Types). Figure 1 shows the payoff functions of each type over the tax rate, for communities of four agents (separate) and communities of eight agents (pooled). The range of taxes for which the High Types receive higher payoffs by pooling their resources in an 8-person community than by segregating in a 4-person community with their optimal tax policy of 85 is: $t \in(19.72,227.7)$. On the other hand, the Low Types would receive higher payoffs from pooling only if the larger community offered a tax in the range $t \in(1.16,13.4)$. As these ranges do not overlap, there is no tax rate for which both types would receive higher payoffs by being in a single community than they would by separating.

\section{Experimental Design}

All experimental sessions were conducted at the Harvard Decision Science Laboratory in Cambridge, Massachusetts. Participation was restricted to graduate and undergraduate students. Though most participants were Harvard University students, other local universities such as Boston University, Tufts University, and Northeastern University were also represented. Subjects participated in groups of 16 or 24 people at a time, and interacted with seven anonymous others in the room using the experimental software z-Tree (Fischbacher 2007). In other words, each session 
was populated by eight subjects, with two or three sessions running concurrently to ensure that subjects did not know which participants were in their own session. Of the eight subjects in each session, four were randomly assigned to be "High Types," who greatly benefited from public good provision in their community and for whom the optimal tax rate was 85 . Four were "Low Types," who benefited very little and preferred a tax rate of 5 . In order to maintain the demand revelation problem that Tiebout sorting was proposed to solve, subjects did not receive specific information on the payoffs of the other participants, but were aware that there was variation in the population.

Subjects played a 20-period dynamic game. The number of periods was common knowledge. In each period, they first chose a location and then made a contribution to the local public good. There were six available locations, which remained the same for the duration of the experiment, and were labeled "Group 1" through "Group 6." Subjects received information on the previous outcomes in all of the locations, but not the location or contributions of specific individuals. The method of determining the contribution the subjects made depended on the institution governing their session. The four institutions were Voluntary Contributions, Fixed Tax, Fixed Quantity, and Voting.

In the Voluntary Contributions (VCM) sessions, each subject could contribute however much they wished. The latter three institutions required all members of a community to make identical contributions.

Under the Fixed Tax institution, each of the locations was associated with a fixed, posted tax $(t)$. Anyone who entered the location was required to contribute this amount in each period, for the duration of their time in that location. The provision quantity then depended on the number of residents who entered (i.e., $t$ times the number of residents).

Under the Fixed Quantity institution, each location was associated with a fixed, posted provision quantity $(X)$ that was provided in this location in every period in which it was populated. The per capita taxes were then dependent upon the number of residents who entered (i.e., $X$ divided by the number of residents). Among the available locations in the Fixed Tax and Fixed Quantity conditions were those offering the optimal bundles for each of the preference types in the experiment. These institutions are most similar to Tiebout's description of communities as offering public goods packages that remained fairly constant over time. One can also think of these institutions as capturing a form of local government that is not highly responsive to the preferences of its constituents, such that local policies are entrenched.

Finally, under the Voting institution, the location's current members voted on the local tax policy in each period. The median voter's preference was implemented and all members were then required to contribute this amount in the period. In the case of even-numbered populations, the two median votes were averaged. The preference aggregation mechanism was fully explained to the subjects. Instructions for all four treatments are provided in the online Appendix.

A total of 17 sessions were run: five sessions under the Voting institution and four under each of the other three institutions. Under all four institutions, the subjects' payoffs were given by equation (2), with $A=85$ for High Types and $A=5$ for Low Types. Subjects were not presented with this equation directly. Instead, each subject 
was given a table showing his payoff for each possible outcome. These payoff tables were provided on paper so that the subjects could refer to them throughout the experiment. In the VCM sessions, the table showed what the subject's payoff would be for various combinations of personal contributions (shown in columns) and total contributions in the community (shown in rows). For each tax institution, the table showed the subject's payoffs for various tax or expenditure policies (columns) and community sizes (rows). Thus, the subjects could use the table to determine what their payoff would be in any location, based on their expectation of the number of residents or the total voluntary contributions. The experiment began only after all participants correctly answered a series of comprehension questions regarding the procedure and their payoffs.

The sessions each followed the same basic procedure. At the start of each period, subjects simultaneously selected the location they wished to enter. They then submitted a contribution and received their payoff for the period. Finally, they observed the outcomes in each location over the previous three periods before making their next move. In all conditions, this information included the number of residents in each location, with the subject's personal, realized payoff listed under the location he had resided in that period. Subjects also saw the fixed policies associated with the locations (in the Fixed Tax and Fixed Quantity conditions), the previously enacted tax policies (in the Voting condition), or the total and personal contributions (in the Voluntary Contributions condition). 9

In the first period, all subjects, in all conditions, began in the same initial location. The policy of this location under the Fixed Tax and Fixed Quantity institutions was selected to be the same as the policy enacted in the Voting condition if all subjects voted for their ideal policy. ${ }^{10}$ Moving-selecting a different location than in the previous period — carried a cost of five experimental units.

Finally, note that communication was not permitted. Though communication is feasible in a small-scale lab experiment (and could facilitate efficient sorting in this context), in most cases it is implausible that communication could occur on the scale necessary to enable individuals to identify likeminded households, even within their own community, and to then coordinate movement.

\section{A. Theoretical Predictions}

A partition of agents is Nash stable if there does not exist any agent who would receive a higher payoff by unilaterally moving to a different location. A partition of agents is strong Nash stable if there does not exist any set of agents, all of whom would receive a weakly higher payoff and at least one of whom would receive a strictly higher payoff by coalitionally moving to different locations.

\footnotetext{
${ }^{9} \mathrm{~A}$ chart showing the available information while making location choices is given by Table 3 in the online Appendix.

${ }^{10}$ The initial condition was chosen to keep the conditions as consistent as possible under each institution. Since over four-fifths of subjects in the Fixed Tax and Fixed Quantity sessions leave their initial group within the first two periods, the initial choice is unlikely to unduly influence the remainder of the session. Further, there is no difference in efficiency outcomes between Voting sessions that implemented the predicted tax and those that did not.
} 
Since the public good is pure, the state in which the entire population resides in a single location is strong Nash stable under Voluntary Contributions. However, under the Nash equilibrium contributions, this community under-provides the public good; the Low Types do not contribute anything and the High types contribute 85 among the four of them. Thus, the total provision level is equal to 85 , less than $1 / 4$ of the optimal level for the population.

The payoffs for the two types are sufficiently different that there exists a unique strong Nash equilibrium under Fixed Tax, Fixed Quantity, and Voting in which the two types separate into two homogeneous communities where they consume the optimal tax provision pair for their type. In this state, the Low Types are together in a location with $(t, X)=(5,20)$ and the High Types are together in a location with $(t, X)=(85,340)$.

However, under both Fixed Tax and Fixed Quantity, two forms of suboptimal Nash equilibria exist. In the first, the types separate and consolidate but are in locations where the tax policy differs from the optimal policy for that population. Specifically, consider a state in which all four High Types are in a single community with $\operatorname{tax} t_{H}$ and all four Low Types are in a different, single community with tax $t_{L}$. Though High Types would prefer that $t_{H}=85$ and Low Types would prefer $t_{L}=5$, any state in which all four High Types are together paying $t_{H} \in[8.7,315]$, all four Low Types are together paying $t_{L} \in[0.5,18.5]$, and $t_{H}$ sufficiently ${ }^{11}$ differs from $t_{L}$, is Nash stable.

The second form of suboptimal Nash stable states occur when the types are pooled in a single community with an intermediate tax policy. Any state in which all members are together in a community with tax $t \in[4,23]$ is Nash stable, as no subject would wish to independently exit a community of 7 others in favor of striking out on his own. Both of these suboptimal outcomes are eliminated as equilibria under the Voting institution.

\section{Ultimate Outcomes and Efficiency}

This section examines the outcomes that the subjects reach by the end of their experimental session. The efficiency of the outcomes to which subjects converge varies greatly across institutions. When contributions are voluntary, subjects attain payoffs significantly below those of the Nash equilibrium. The subjects under both the Fixed Tax and Fixed Quantity institutions attain moderate payoffs, while the payoffs of those under the Voting institution nearly reach the strong Nash payoffs. Subjects sort into homogeneous communities under all three of the tax institutions, and these differences in efficiency are the result of subjects under the Fixed Tax and Fixed Quantity institutions providing a level of the public good that differs from their optimum.

\footnotetext{
${ }^{11}$ Specifically, $5 \ln \left(4 t_{L} / 5 t_{H}\right)<t_{H}-t_{L}<85 \ln \left(4 t_{H} / 5 t_{L}\right)$ must hold in addition to the above tax ranges.
} 


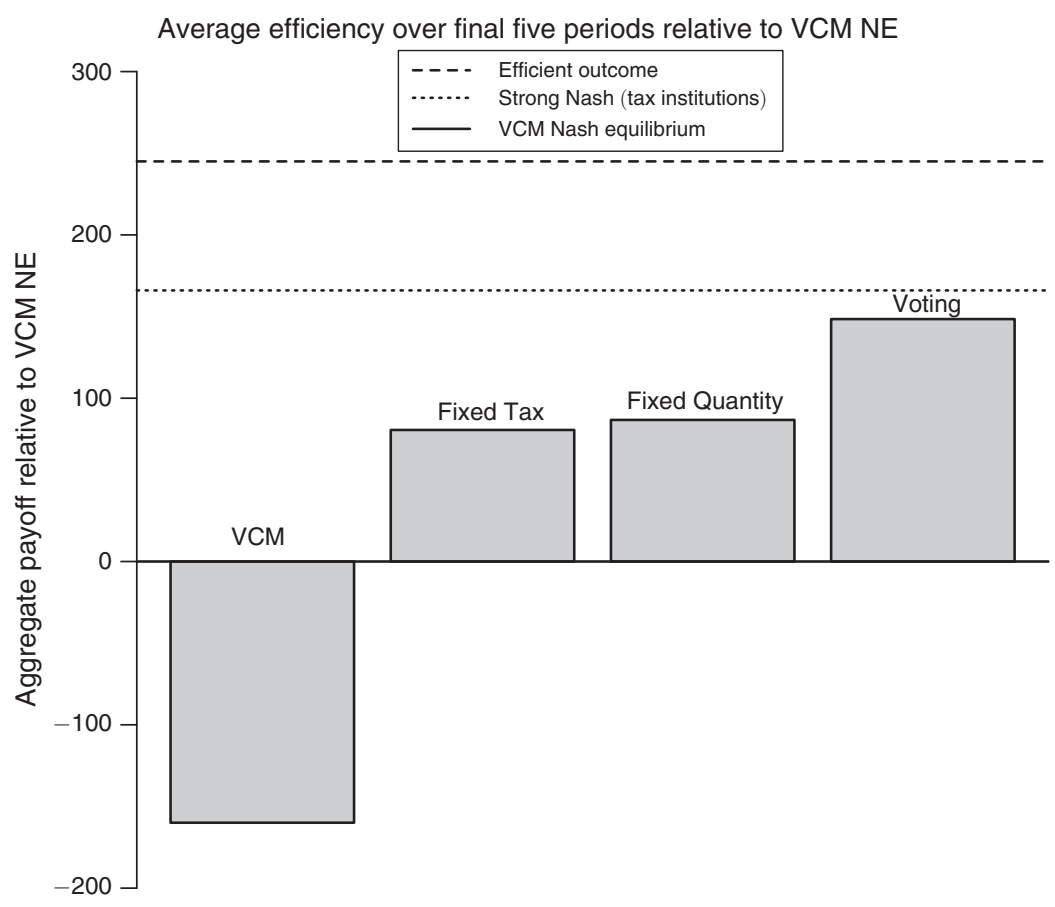

Institution

Figure 2. Average EfFiciency Under Each Institution

\section{A. Efficiency Convergence}

I first compare efficiency convergence under the four institutions, relative to the baseline of the Nash equilibrium prediction under Voluntary Contributions, in which all subjects locate together, but the public good is severely under-provided. The voluntary contribution Nash equilibrium is taken as the baseline since it is both the outcome that Tiebout was attempting to improve upon and the outcome to which standard public goods games tend to converge. The average efficiency over the final 5 periods of the 20-period experiment under each institution is given in Figure 2.12 The most efficient outcome is represented by the dashed line, but is achievable only when residents can solve the demand revelation problem within a single community. The strong Nash equilibrium is the highest feasible outcome when residents sort into multiple communities, and is represented by the dotted line.

First, we see that the subjects achieve very low payoffs when contributions are voluntary, even relative to the Nash equilibrium prediction, suggesting that they are squandering their resources. Subjects may do worse than the Nash equilibrium outcome if they either locate in a single location, but contribute less than the Nash equilibrium provision, or locate across multiple locations and diffuse their resources

\footnotetext{
${ }^{12}$ Efficiency is smoothed over the final five periods so as to avoid over or underemphasizing incidental deviations.
} 
(or both). Further investigation into the cause of this inefficiency follows in the next section. Efficiency under both Fixed Tax and Fixed Quantity is significantly greater than the baseline, at 33 percent and 35 percent, respectively, or approximately 50 percent of the strong Nash outcome. ${ }^{13}$ Finally, efficiency under Voting is significantly higher, and nearly reaches the strong Nash outcome. Thus, while the Fixed Tax and Fixed Quantity institutions lead to moderate improvements in efficiency relative to our baseline, they still fall short of facilitating efficient public good provision, and only under Voting do the subjects approach the optimal allocation. ${ }^{14}$

\section{B. Sources of Inefficiency}

There are two distinct causes of inefficiency in this environment. Subjects may fail to properly sort by type or, upon sorting, may fail to provide the optimal level of public good for their community.

I first look at whether subjects reach a sorted partition. Figure 3 shows the proportion of time, over the final five periods of the experiment, that the types are sorted into two separated, consolidated groups. A subject is considered "sorted" if he is in a location with at least two of the three others of his type, and with no more than one member of the other type.

For all three institutions under which community members must contribute equal amounts, subjects are highly successful in sorting into two homogeneous groups. Over the final 5 periods, subjects in these 3 conditions are sorted 94 percent of the time. While there is little difference in community composition by the end of the 20-period sessions under Fixed Tax, Fixed Quantity, and Voting, the institutions do vary in how rapidly subjects sort. Subjects require an average of 2.5 periods to first reach a sorted partition under Fixed Tax, 3.6 periods under Fixed Quantity, 5.95 periods under Voting, and 10.2 periods - if ever-under VCM. ${ }^{15}$

Although subjects are eventually well-sorted under all three tax institutions, the question remains as to whether they provide the optimal level of public goods for their type within these homogeneous communities. The average and percentage difference between what subjects actually pay and their optimal contribution are shown in Figure 4. Note that this includes both over- and under-contribution relative to the optimum. Unsurprisingly, contributions greatly differ from the optimal amounts when provision is voluntary. However, High Types under Fixed Tax and

\footnotetext{
${ }^{13}$ The difference is significant at the $p<0.01$ level and significant at the $p=0.04$ level when either clustering errors at the session level or treating each session as a single observation.

${ }^{14}$ The effect of institution on efficiency is significant at $p<0.01(F=6.76$, where the unit of observation is 1 session). Voting efficiency is significantly higher than Fixed Tax and Fixed Quantity efficiency: $p=0.02 ; p=0.063$ when clustering at session level (as recommended by Fréchette 2012); and $p=0.076$ using the wild cluster bootstrap with imposed null hypothesis (as recommended by Cameron, Gelbach, and Miller 2008). The $p$-values were calculated using Doug Miller's percentile- $t$ cluster bootstrap do file (http://www.econ.ucdavis.edu/faculty/dlmiller/ statafiles/bs_example.do).

${ }^{15}$ The difference between Fixed Tax and Fixed Quantity sessions is not significant $(p=0.33)$. The number of periods necessary to reach a sorted partition under Voting is significantly higher than Fixed Quantity at the 0.05 level and lower than VCM at the $<0.01$ level. The additional time needed to sort in the Voting sessions appears to be the result of two complementary factors. First, it takes some time for communities to implement the optimal tax rates, that motivate movement; and, second, the absence of posted tax rates means that it takes longer for subjects to find similar individuals and coordinate into two locations.
} 
Separated, consolidated groups (final five periods)

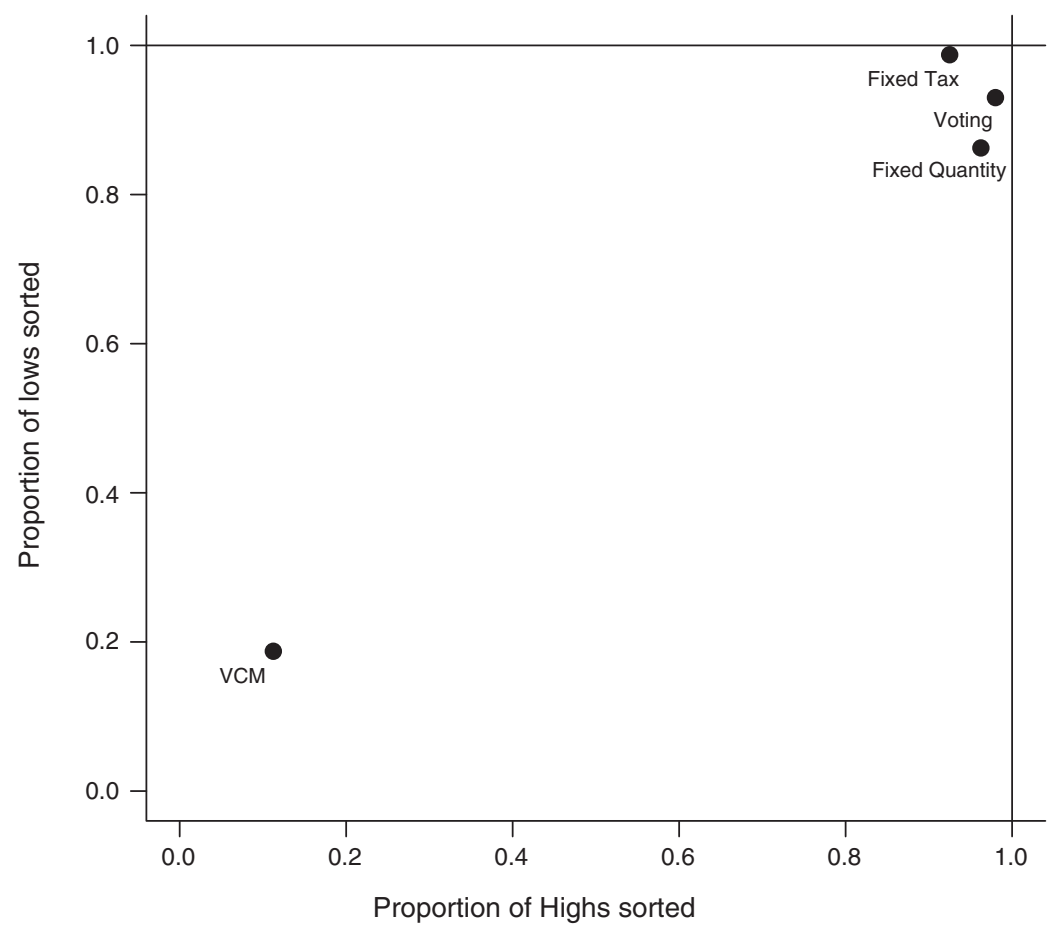

Figure 3. Sorting by Type in the Final Five Periods

Panel A. Average deviation from optimal contribution (final five periods)

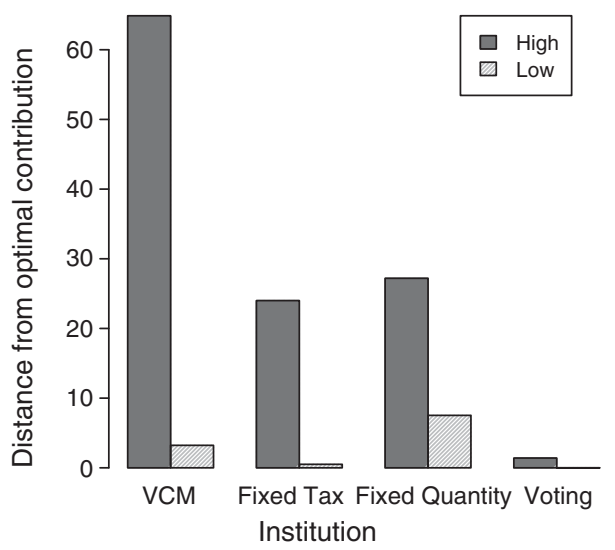

Panel B. Percent deviation from optimal contribution (final five periods)

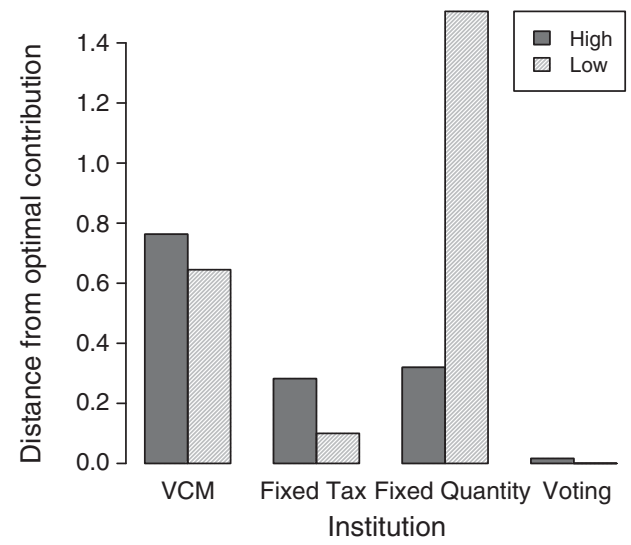

Figure 4. Average and Percentage Absolute Deviation from Optimal Contribution IN THE FINAL FIVE PERIODS (Includes both over- and under-contribution relative to optimum)

Fixed Quantity, as well as Low Types under Fixed Quantity, often deviate from their optimal contribution as well. Over the final 5 periods, High Types' contributions differ from their optimum by approximately 30 percent under both of these institutions, and Low Types' contributions differ from their optimum by 150 percent under Fixed 
Quantity. Thus, instead of reaching the strong Nash stable outcome, subjects tend to get stuck at inefficient Nash stable equilibria under these institutions. The dynamics that cause subjects to sort themselves into communities with suboptimal policies are further explored in the following section. Finally, when subjects are able to vote for their local tax rate, contributions differ from optimal levels by 0.8 percent overall.

\section{Dynamic Results}

I next consider the dynamics under each of the four institutions that lead to these final outcomes. Although the subjects under the VCM institution contribute, on average, at the Nash equilibrium level, perpetual movement through locations leads to efficiency below that of the Nash equilibrium. Under the institutions requiring all members of a community to contribute the same amount, the High Types very rarely exit large communities with many taxpayers. In the Fixed Tax and Fixed Quantity sessions, this unwillingness to move into less-populated locations often results in the subjects becoming stuck at less efficient equilibria, in which public good provision differs from the optimum for their type. Finally, under the Voting institution, the communities converge to the optimal provision for their populations.

\section{A. Voluntary Contributions}

The top left panel of Figure 5 shows the average contribution over time for each of the two types under the VCM institution. This graph suggests that, although the subjects are free riding, they are converging toward the equilibrium contribution level, and that the severe inefficiency we see in Figure 2 is therefore not driven by under-contribution relative to the Nash equilibrium level.

Instead, the inefficiency seems to be caused by the subjects moving frequently and dispersing their resources over multiple locations. Although a partition with all members of the population in a single location is both efficient and strong Nash stable in the VCM sessions, subjects do exit the all-inclusive community and they continue to move over the course of the session. The subjects are together in a single location in only half of all periods. While movement significantly declines over time, under all three institutions with local mandatory tax rates, there is no such stabilization under Voluntary Contributions and, toward the end of the session, movement occurs with more than twice the frequency of the other institutions. In a free-answer survey conducted after the experiment, over 20 percent of subjects in the VCM session said that their primary motivation for moving was that other group members were contributing less than they were. ${ }^{16}$

Even though it is the High Types who benefit most from being in communities providing the public good, they are the ones who typically initiate this movement by exiting large communities in favor of smaller ones or previously empty locations.

\footnotetext{
${ }^{16}$ The results of these surveys are tabulated and presented in Tables 1 and 2 in the online Appendix. This finding is consistent with the large body of experimental literature showing that subjects are willing to sacrifice their own payoff in order to "punish" those who are not behaving cooperatively, either via an explicit punishment mechanism (Fehr and Gächter 2000); making a Pareto damaging choice (Güth, Schmittberger, and Schwarze 1982; Charness and Rabin 2002); or by exiting a partnership (Hauk 2003).
} 
Panel A. VCM average contribution over time

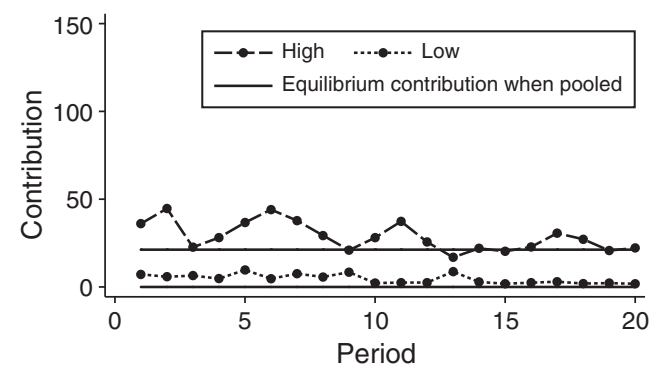

Panel C. Fixed Quantity:

Average contribution over time

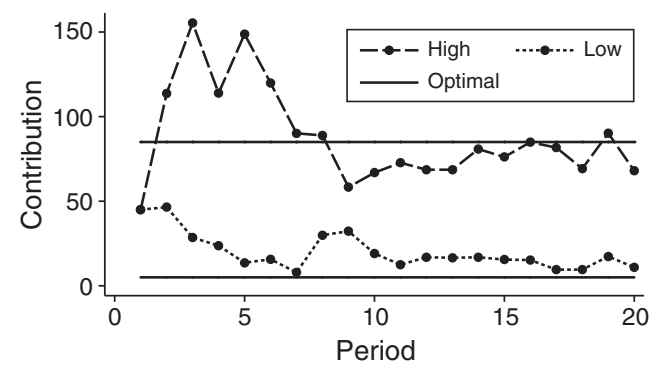

Panel B. Fixed Tax:

Average contribution over time

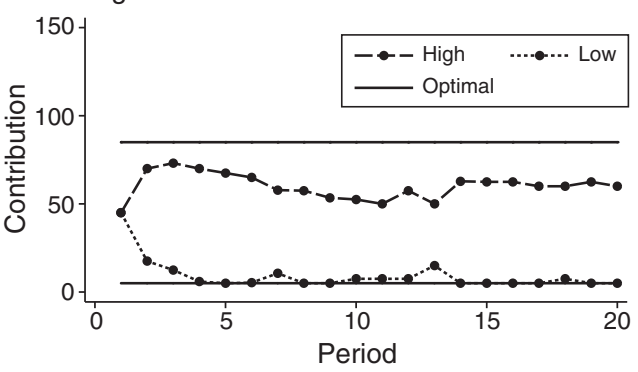

Panel D. Voting: Average contribution over time

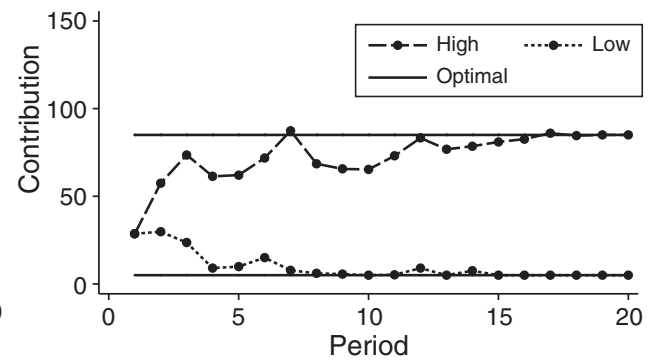

Figure 5. Average Contributions Over Time under Each Institution

Notes: This figure reports the average contributions over time for high types and low types under each of the four institutions. The two solid lines in the VCM panel show the Nash equilibrium average contribution for the High Types (21.25) and the Low Types (0). The two solid lines in each of the three tax institution panels show the optimal tax rates for the High Types (85) and the Low Types (5).

On average, High Types who move enter communities that previously contained 0.79 fewer members than their own (not including themselves), while Low Types move to slightly larger communities, containing 0.34 more members than the community they exited. ${ }^{17}$ These dynamics are similar to those previously found in a linear, pure public goods environment, when subjects with different returns from the public good could move between locations. ${ }^{18}$ There is a difference, however, in the efficiency relative to the Nash equilibrium in the two environments. Since equilibrium contributions are zero in a linear VCM, the public good is not provided and thus the agent's equilibrium payoffs do not depend on his group. But in an environment where public goods are provided in equilibrium, agents benefit from being in larger communities, and frequent movement may be harmful. In this environment, the ability to move leads to worse outcomes for the subjects than if they played the Nash equilibrium within a fixed group, implying that mobility is detrimental to efficiency.

\footnotetext{
${ }^{17}$ The difference in community size exited - community size entered between the two types is significant at the 0.1 level.

${ }^{18}$ Robbett (2010).
} 
TABLe 1-Fixed EfFects Regressions of Earnings on Movement

\begin{tabular}{lcccc}
\hline \hline & \multicolumn{4}{c}{ Dependent variable: Current period payoff } \\
\cline { 2 - 5 } & $(1)$ & $(2)$ & $(3)$ & $(4)$ \\
\hline Move & $-19.97^{* * *}$ & -8.15 & $-19.97^{*}$ & -8.15 \\
Community size & $(5.62)$ & $(6.16)$ & $(7.04)$ & $(6.09)$ \\
& - & $5.20^{* * *}$ & - & $5.20^{*}$ \\
Contribution & - & $(1.19)$ & - & $(1.88)$ \\
& $-0.48^{* * *}$ & $-0.449 * * *$ & $-0.48^{*}$ & $-0.449 *$ \\
Intercept & $(0.05)$ & $(0.05)$ & $(0.17)$ & $(0.18)$ \\
& $187.95^{* * *}$ & $153.4 * * *$ & $187.95^{* * *}$ & $153.4 * * *$ \\
Observations & $(2.13)$ & $(8.18)$ & $(4.27)$ & $(13.7)$ \\
Clusters & 640 & 640 & 640 & 640 \\
\hline
\end{tabular}

Notes: This table reports estimates and standard errors from regressions in which each observation represents one subject-period in the VCM sessions. The variable move equals 1 if the subject chose a different location than the previous period, community size is the number of individuals in the current location, and contribution is the individual's own contribution in the current period. Subject fixed effects are included. Standard errors are in parentheses and are clustered at the session level in columns 3 and 4.

*** Significant at the 1 percent level.

** Significant at the 5 percent level.

* Significant at the 10 percent level.

Finally, we look at the extent to which frequent movement is associated with lower payoffs under Voluntary Contributions. I first consider the within-subjects effect of moving on the current period's earnings. Table 1 presents regressions of period earnings on the subject's movement decision and contribution decision, using subject-specific fixed effects. Movement is associated with a large, immediate loss. Furthermore, this is no longer significant when controlling for the size of the community that the subject enters. However, this model captures only the immediate impact of moving on earnings. Even if a subject suffers a one-period loss of earnings as a result of moving, he may have bettered his position for the periods to follow. To address this possibility, I next treat each subject as a unique observation and look at the association between the number of times that the subject moved and the subject's total earnings for the entire session. Table 2 presents OLS regression results of the subject's total payoffs on his frequency of movement and his own average contribution. Those subjects who move frequently earn significantly less during the course of the experiment. 19

\footnotetext{
${ }^{19}$ Since we are looking only at VCM sessions, clustering at the session-level gives only four clusters. In Tables 1 and 2, the standard errors are reported with and without clustering and the results are comparable. Since the wild bootstrap is not recommended for fewer than than five clusters, this method was not used. Note that Table 2 also suggests that movement is relatively more harmful for Low Types, who move less often. I thank an anonymous referee for pointing out this additional tie to the punishment literature, which has consistently found that individuals punish less as it becomes more costly to do so.
} 
TABle 2-OLS Regressions of Total Earnings on Number of Moves

\begin{tabular}{lcccc}
\hline \hline & \multicolumn{4}{c}{ Dependent variable: Subject's final payoff } \\
\cline { 2 - 5 } & High Types & Low Types & High Types & Low Types \\
\hline Moves & $-162.7 * * *$ & $-29.08 * * *$ & $-162.7 * *$ & $-29.02 * * *$ \\
\multirow{2}{*}{ Average contribution } & $(53.57)$ & $(4.5)$ & $(43.72)$ & $(4.51)$ \\
& 4.8 & $-12.9 * * *$ & 4.8 & $-12.9 * * *$ \\
Intercept & $(9.59)$ & $(3.07)$ & $(14.03)$ & $(1.68)$ \\
& $7,142 * * *$ & $416 * * *$ & $7,142 * * *$ & $416 * * *$ \\
$R^{2}$ & $(384.5)$ & $(21.8)$ & $(727)$ & $(40.4)$ \\
Observations & 0.42 & 0.83 & 0.42 & 0.83 \\
Clusters & 16 & 16 & 16 & 16 \\
\hline
\end{tabular}

Notes: This table reports estimates and standard errors from OLS regressions in which each observation represents one subject in the VCM sessions. The variable moves refers to the total number of times the subject switched locations and average contribution is the individual's mean contribution to the public good over all periods. Standard errors are in parentheses and are clustered at the session level in columns 3 and 4.

*** Significant at the 1 percent level.

** Significant at the 5 percent level.

* Significant at the 10 percent level.

\section{B. Fixed Tax and Fixed Quantity}

The Fixed Tax and Fixed Quantity institutions are most similar to the environment envisioned by Tiebout: there exist many communities offering a wide range of exogenously determined local policies that remain constant over time. The residents, in turn, select the community whose tax-provision pair best suits them, but do not influence the local policies in their chosen community. Under the Voluntary Contributions institution, we saw that High Types were more likely to exit larger groups in favor of smaller ones, while Low Types were attracted to areas populated by contributing High Types. When communities have mandatory local taxes, this dynamic is reversed: the Low Types now flee the taxes, while the High Types are less likely to exit areas with other taxpayers. The Low Types exit the all-inclusive group in their first opportunity 93.75 percent of the time under the Fixed Tax and Fixed Quantity institutions, while less than half of the High Types do so. The left panel of Figure 6 shows the average size of the community a subject exits, relative to the size of the community he enters, for each of the two types under both Voluntary Contributions and the exogenous tax policy institutions (Fixed Tax and Fixed Quantity). The right panel of Figure 6 shows how the likelihood that a high type exits his community declines over the number of other High Types in the community, both when this community provides the optimal policy and when it does not. Although the High Types exit communities with policies that differ from their optimum more frequently, they rarely exit when two or three other High Types are present. ${ }^{20}$

\footnotetext{
${ }^{20}$ Probit regressions confirm that the number of High Types has a strong, significant effect on the exit decision: the presence of an additional High Type is associated with a 14 percent lower likelihood of exit in the following period ( $p<0.01$ when clustering errors at the session level), whereas whether the subject is in a community with their optimal policy has a negligible effect.
} 
Panel A. Average difference in community size (exited - entered)

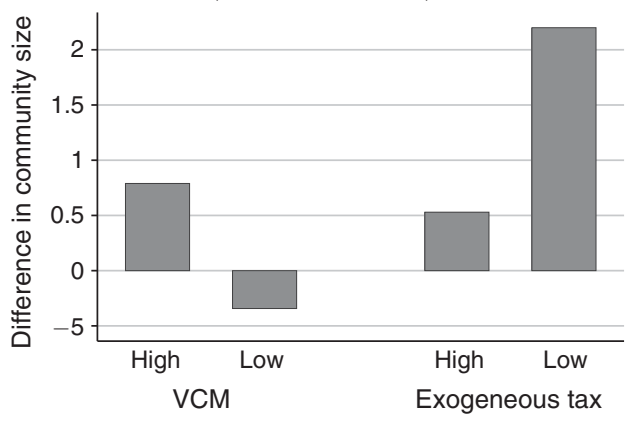

Panel B. Likelihood of High Type exit by number of highs in current location

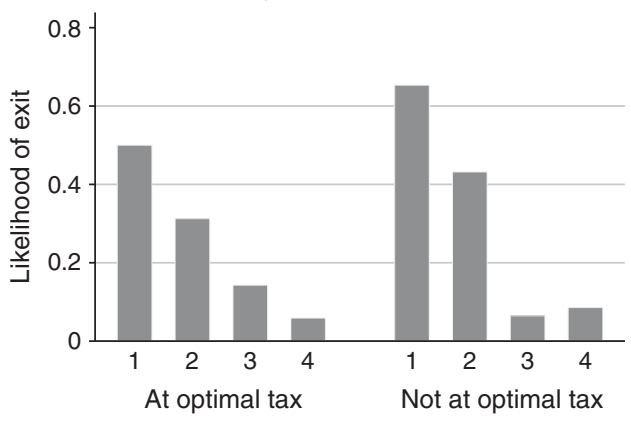

Figure 6. The Importance of Community Size in Movement Decisions of the High Types

This unwillingness of High Types to exit larger communities causes them to be susceptible to a coordination failure such that, despite consolidating into a location with other High Types, they fail to attain the optimal tax and provision levels for their type. Figure 5 shows the average contribution over time under Fixed Tax (top right panel) and under Fixed Quantity (bottom left panel).

Once a subject arrives in a Nash stable state, he is unlikely to exit. While subjects who are in a state that is not Nash stable exit the majority of the time, subjects who do arrive in a Nash stable state exit in only 6.6 percent of opportunities. In the case in which subjects sort themselves into a state that is Nash stable but not strong Nash stable, subjects will stay approximately 92 percent of the time.

\section{Voting}

While subjects under the Voting institution take longer to sort themselves into two homogeneous communities than under Fixed Tax or Fixed Quantity, once they coordinate they are less likely to move, as they are able to set their tax within the location. Furthermore, 92.5 percent of subjects vote for their optimal tax policy by the end of the session, and so the optimal policies for each type are eventually implemented within the sorted communities. The bottom right panel of Figure 5 shows that the contributions of each type converge to their optimum under the Voting institution.

Thus, mobility is most successful when communities have an internal process by which residents may adjust their local policies without being required to relocate. The ability to vote with one's feet allows types to separate and coordinate by moving to a community of similar types. Subjects implementing their own local policies require only a few more periods to coordinate into separate, homogeneous communities than those choosing among locations with fixed policies. The ability to vote with one's ballot then allows the residents to adapt the community to their preferences, reducing the possibility that a community of like-minded residents fails to realize the policy best suited for them. 


\section{Conclusion}

This paper uses laboratory experiments to study the dynamics of movement and local public good provision in a simple Tiebout environment and to test the effectiveness of four different institutions in facilitating efficient public good provision. The results suggest that institutions determining the level of the local public good provision within a community can greatly affect residents' ability to coordinate with those who share their preferences, and to converge to an optimal outcome.

Voluntary contributions communities enable residents with different preferences to make different contributions, without the need to relocate or divide their resources over multiple communities, but are susceptible to the same free riding and demand revelation problems that can plague public good provision at the federal level. This paper finds that voluntary contributions communities are characterized by free riding, instability, and inefficient movement, and replicates the dynamics previously found in local pure linear public goods games with two types of agents. This suggests that these patterns and instability are robust to differences in the payoff function, with one distinction: when public goods are provided in equilibrium, this frequent movement may lead to efficiency significantly below equilibrium predictions, and mobility may actually be harmful to efficiency.

Taxes requiring all members of a community to make the same contribution to the local public good are highly successful at sorting subjects by preferences into consolidated, homogeneous communities. However, subjects often coordinate into, and remain in, communities offering suboptimal tax-provision bundles for their type. This inertia suggests that mobility in itself is not sufficient for achieving an optimal allocation of public goods and that the existence of optimally designed policies is not sufficient for guaranteeing that communities offering these policies will be entered.

When subjects have an internal process for adapting the policies of the communities they have entered, the local communities converge to the optimal policies for their residents. While subjects require slightly longer to sort into homogeneous communities when fixed local policies are not provided, they are eventually just as successful at reaching an optimal partition and, when they can then vote on the local policy, residents converge toward consuming their optimal level of public goods.

Tiebout ended his discussion by asking whether local governments should have fixed expenditure policies (Tiebout 1956, 423). The results of this experiment suggest that agents with very different preferences will sort by preference type even when communities do not provide exogenous tax policies, and that local politics may be necessary for overcoming coordination problems, adjusting provision to the preferences of the residents, and reaching an efficient allocation.

\section{REFERENCES}

Ahn, T. K., R. Mark Isaac, and Timothy C. Salmon. 2008. "Endogenous Group Formation.” Journal of Public Economic Theory 10 (2): 171-94.

Ahn, T. K., R. Mark Isaac, and Timothy C. Salmon. 2009. "Coming and Going: Experiments on Endogenous Group Sizes for Excludable Public Goods.” Journal of Public Economics 93 (1-2): 336-51. 
Banzhaf, Spencer H., and Randall P. Walsh. 2008. "Do People Vote with Their Feet? An Empirical Test of Tiebout's Mechanism.” American Economic Review 98 (3): 843-63.

Been, Vicki, and Francis Gupta. 1997. "Coming to the Nuisance or Going to the Barrios? A Longitudinal Analysis of Environmental Justice Claims.” Ecology Law Quarterly 24: 1-56.

Bishop, Bill. 2008. The Big Sort: Why the Clustering of Like-Minded America Is Tearing Us Apart. New York: Houghton Mifflin.

Bureau of the Census. 2000-2010. Current Population Survey Data on Geographical Mobility/Migration. Bureau of the Census. Washington, DC. http://www.census.gov/hhes/migration/data/cps.html (accessed July 19, 2011).

Cameron, A. Colin, Jonah B. Gelbach, and Douglas L. Miller. 2008. "Bootstrap-Based Improvements for Inference with Clustered Errors." Review of Economics and Statistics 90 (3): 414-27.

Cameron, Trudy Ann, and Ian T. McConnaha. 2006. "Evidence of Environmental Migration." Land Economics 82 (2): 273-90.

Charness, Gary, and Matthew Rabin. 2002. "Understanding Social Preferences with Simple Tests." Quarterly Journal of Economics 117 (3): 817-62.

Charness, Gary, and Chun-Lei Yang. 2010. "Public Goods Provision with Voting for Exclusion, Exit, and Mergers: An Experiment.” http://www.econ.ucsb.edu/ charness/papers/endogenous_092210.pdf.

Costa, Dora L., and Matthew E. Kahn. 2000. "Power Couples: Changes in the Locational Choice of the College Educated, 1940-1990.” Quarterly Journal of Economics 115 (4): 1287-1315.

Dowding, Keith, Peter John, and Stephen Biggs. 1994. "Tiebout: A Survey of the Empirical Literature." Urban Studies 31 (4-5): 767-98.

Ehrhart, Karl-Martin, and Claudia Keser. 1999. "Mobility and Cooperation: On the Run." Centre interuniversitaire de reserche en analyse des organisations (CIRANO) Working Paper 99s-24.

Epple, Dennis, Radu Filimon, and Thomas Romer. 1984. "Equilibrium among Local Jurisdictions: Toward an Integrated Treatment of Voting and Residential Choice." Journal of Public Economics 24 (3): 281-308.

Epple, Dennis, Radu Filimon, and Thomas Romer. 1993. "Existence of Voting and Housing Equilibrium in a System of Communities with Property Taxes." Regional Science and Urban Economics 23 (5): 585-610.

Fehr, Ernst, and Simon Gächter. 2000. "Cooperation and Punishment in Public Goods Experiments." American Economic Review 90 (4): 980-94.

Fischbacher, Urs. 2007. “z-Tree: Zurich Toolbox for Ready-Made Economic Experiments.” Experimental Economics 10 (2): 171-78.

Fox, William F., Henry W. Herzog, Jr., and Alan M. Schlottman. 1989. "Metropolitan Fiscal Structure and Migration." Journal of Regional Science 29 (4): 523-36.

Fréchette, Guillaume R. 2012. "Session-effects in the laboratory." Experimental Economics 15 (3): 485-98.

Gramlich, Edward M., and Daniel L. Rubinfeld. 1982. "Micro Estimates of Public Spending Demand Functions and Tests of the Tiebout and Median-Voter Hypotheses." Journal of Political Economy 90 (3): 536-60.

Greenstone, Michael, and Justin Gallagher. 2008. "Does Hazardous Waste Matter? Evidence from the Housing Market and the Superfund Program.” Quarterly Journal of Economics 123 (3): 951-1003.

Gürerk, Özgür, Bernd Irlenbusch, and Bettina Rockenbach. 2006. "The Competitive Advantage of Sanctioning Institutions." Science 312 (5770): 108-11.

Güth, Werner, Rolf Schmittberger, and Bernd Schwarze. 1982. "An Experimental Analysis of Ultimatum Bargaining." Journal of Economic Behavior \& Organization 3 (4): 367-88.

Hauk, Esther. 2003. "Multiple Prisoner's Dilemma Games with(out) an Outside Option: An Experimental Study." Theory and Decision 54 (3): 207-29.

Kollman, Ken, John H. Miller, and Scott E. Page. 1997. "Political Institutions and Sorting in a Tiebout Model." American Economic Review 87 (5): 977-92.

Konishi, Hideo. 1996. "Voting with Ballots and Feet: Existience of Equilibrium in a Local Public Good Economy. Journal of Economic Theory 68: 480-509.

Ledyard, John O. 1995. "Public Goods: A Survey of Experimental Research." In The Handbook of Experimental Economics, edited by Alvin E. Roth and John H. Kagel, 111-94. Princeton: Princeton University Press.

Oates, Wallace. 2006. "The Many Faces of the Tiebout Model." In The Tiebout Model at Fifty: Essays in Public Economics in Honor of Wallace Oates, edited by William A. Fischel. Cambridge, MA: Lincoln Institute of Land Policy.

Page, Talbot, Louis Putterman, and Bulent Unel. 2005. "Voluntary Association in Public Goods Experiments: Reciprocity, Mimicry and Efficiency.” Economic Journal 115 (506): 1032-53. 
Percy, Stephan L., Brett W. Hawkins, and Peter E. Maier. 1995. "Revisiting Tiebout: Moving Rationales and Interjurisdictional Relocation.” Publius 25 (4): 1-17.

Reschovsky, Andrew. 1979. "Residential Choice and the Local Public Sector: An Alternative Test of the "Tiebout Hypothesis." Journal of Urban Economics 6 (4): 501-20.

Rhode, Paul W., and Koleman S. Strumpf. 2003. "Assessing the Importance of Tiebout Sorting: Local Heterogeneity from 1850 to 1990.” American Economic Review 93 (5): 1648-77.

Robbett, Andrea. 2010. "Community Dynamics in the Lab: Congestion, Public Good Provision, and Local Instability.” California Institute of Technology Social Science Working Paper 1339.

Robbett, Andrea. 2014. "Local Institutions and the Dynamics of Community Sorting: Dataset." American Economic Journal: Microeconomics. http://dx.doi.org/10.1257/mic.6.3.136.

Stein, Robert M. 1987. “Tiebout's Sorting Hypothesis.” Urban Affairs Review 23 (1): 140-60.

Tiebout, Charles M. 1956. "A Pure Theory of Local Expenditures.” Journal of Political Economy 64 (5): 416-24.

Westhoff, Frank. 1977. "Existence of Equilibria in Economies with a Local Public Good." Journal of Economic Theory 14 (1): 84-112.

Wooders, Myrna H. 1999. "Multijurisdictional Economics, the Tiebout Hypothesis, and Sorting." Proceedings of the National Academy of Science 96 (1): 10585-87. 